\title{
Upregulation of microRNA- 100 predicts poor prognosis in patients with pediatric acute myeloid leukemia
}

This article was published in the following Dove Press journal:

OncoTargets and Therapy

20 September 2012

Number of times this article has been viewed

Jin Bai

Aiping Guo²

Ze Hong ${ }^{3}$

Wenxia Kuai ${ }^{3}$

'Department of Pediatrics, Huai'an Hospital to Xuzhou Medical College and Huai'an Second People's Hospital, Huai'an, China; ${ }^{2}$ Department of Pediatrics, Chuzhou Hospital, Huai'an, China; ${ }^{3}$ Department of Pediatrics, Huai'an First People's Hospital, Huai'an, China
Correspondence: Wenxia Kuai Department of Pediatrics, Huai'an First People's Hospital, Nanjing Medical University, 6 Beijing Road West,

Huai'an, Jiangsu 223300, China

$\mathrm{Tel}+865178495230 \mathrm{l}$

Fax +8651784952301

Email kuai_wxia@I63.com
Objective: MicroRNA-100 (miR-100), a small noncoding RNA molecule, acts as a tumor suppressor or an oncogene in different cancers. The aberrant expression of this microRNA has been demonstrated as a frequent event in adult patients with acute myeloid leukemia (AML), but little is known for pediatric AML. The aim of this study was to investigate the expression and clinical significance of miR-100 in pediatric AML.

Methods: The expression levels of miR-100 in bone marrow mononuclear cells were detected by real-time quantitative polymerase chain reaction in a cohort of 106 patients with de novo pediatric AML. The prognostic values of miR-100 in pediatric AML were also analyzed.

Results: Compared with normal controls, upregulation of miR-100 in the bone marrow of pediatric AML patients with statistically significant differences $(P<0.001)$ was found. The expression levels of miR-100 were found to be significantly higher in pediatric AML patients with extramedullary disease, with the French-American-British classification subtype M7, and with unfavorable day 7 response to induction chemotherapy ( $P=0.008,0.001$ and 0.01 , respectively). Moreover, both univariate and multivariate analyses revealed that miR-100 upregulation was associated with poorer relapse-free and overall survival in pediatric AML patients.

Conclusion: This is the first report demonstrating the upregulation of miR-100 in pediatric AML, and its association with poor relapse-free and overall survival. These results suggest that miR-100 upregulation may be used as an unfavorable prognostic marker in pediatric AML.

Keywords: pediatric acute myeloid leukemia, microRNA-100, real-time quantitative PCR, prognosis

\section{Introduction}

Acute myeloid leukemia (AML) represents a heterogeneous group of hematologic malignancies characterized by the uncontrolled proliferation of granulocytic, monocytic, megakaryocytic, or, rarely, erythroid blast cells. ${ }^{1}$ Contrary to many other pediatric malignancies, AML carries a very poor clinical outcome, with a disease-free survival of about $50 \%$ after 5 years in the most successful studies. ${ }^{2}$ Although AML makes up only $15 \%-20 \%$ of pediatric leukemia, it still accounts for $>30 \%$ of deaths from leukemia. ${ }^{3}$ Prognostication of AML is currently dominated by clinical response to induction chemotherapy and cytogenetic analyses. Many clinical features such as favorable cytogenetics (eg, t $[15 ; 17]$, inv[16], and t [8;21] [1-3]) and a good initial treatment response are associated with a good outcome. ${ }^{4}$ However, the diagnosis encompasses a very heterogeneous group of leukemias with distinct response to chemotherapy. ${ }^{5}$ The clinical outcome of pediatric AML patients with similar treatment response varies greatly. Apart from treatment response, the aberrant expressions of several molecules 
are involved in prognosis in pediatric AML. For example, mutations in the FLT3, C-Kit, NPM1, WT1, and CEBPA genes are important with respect to survival and prognosis in pediatric AML. ${ }^{6,7}$ However, the biological determinants for therapy failure are still largely unknown. Therefore, it is necessary to identify novel and effective tumor-related molecules for pediatric AML in order to improve prognostic evaluation levels and to develop more appropriate therapeutic approaches.

MicroRNAs (miRNAs) are a class of small, noncoding RNA molecules of about 22 nucleotides that regulate protein expression by inhibition of translation or degradation of mRNA transcripts, and thus display aberrant expression patterns and functional abnormalities in many human diseases, including cancers. ${ }^{8}$ MiRNAs constitute a number of signaling pathways that play an important role in critical cellular processes like proliferation, differentiation, and apoptosis. Biological evidence suggests that the influence of miRNAs may be dependent on cancer type. ${ }^{9}$ Some miRNAs act as oncogenes by contributing to the transformed phenotype when expressed at high levels in cancers. These oncogenic miRNAs may function by suppressing tumor-suppressor genes. ${ }^{10}$ Some miRNAs act as tumor suppressors, and are weakly expressed or absent in tumors, and act by allowing the expression of oncogenes. ${ }^{10}$ MiRNA expression profiles can be used to classify specific cancers. In leukemia research, Zhang et al indicated that existing pediatric-associated and prognostic parameter-associated miRNAs could provide therapeutic direction for individual risk-adapted therapy for pediatric leukemia patients; ${ }^{11}$ Rücker et al found important roles of the $\mathrm{p} 53-\mathrm{miR}-34 \mathrm{a}$ axis in the disease progression of complex-karyotype AML; ${ }^{12}$ Cimmino and colleagues suggested that a small genomic region in chromosome $13 \mathrm{q} 14$ that is commonly deleted contained $m i R-15-A$ and $m i R-$ 16-1 genes in chronic lymphocytic leukemia; ${ }^{13}$ Lopotová et $\mathrm{al}^{14}$ identified a reciprocal regulatory loop between $B C R-A B L$ and miR-451 as a maintenance mechanism of the leukemic state of chronic myeloid leukemia cells; and the miR-29b-1/29a cluster located at 7q32 has been identified as a region deleted in therapy-related AML and myelodysplastic syndromes. ${ }^{15}$ Regarding our interests, the aberrant expression of miR-100 has been found in various cancer cells. As a potential tumor-suppressive miRNA, the decreased expression of miR-100 has been found in oral cancer, adrenocortical cancer, hepatocellular carcinoma, clear-cell ovarian cancer, and bladder cancer. ${ }^{16-20}$ However, its expression has been demonstrated to be upregulated in adult patients with AML at the time of diagnosis. ${ }^{21}$
miR-100 expression and clinical significance in pediatric AML remain unknown. To address this problem, in the present study we investigated the expression level of miR-100 in bone marrow mononuclear cells by real-time quantitative polymerase chain reaction (PCR) in a cohort of 106 patients with de novo pediatric AML. The prognostic value of this miRNA in pediatric AML was also analyzed.

\section{Materials and methods Patients and tissue samples}

Prior informed consent was obtained from the patients for the collection of specimens in accordance with the guidelines of Huai'an First People's Hospital, China, and the study protocols were approved by Huai'an First People's Hospital Ethics Committee. All specimens were handled and made anonymous according to ethical and legal standards.

One hundred and six patients with de novo pediatric AML were selected from the files of the Department of Pathology, Huai'an First People's Hospital, China. All the patients were younger than 18 years of age (median 6 years) and included 58 boys and 48 girls. The median leukocyte count at diag-

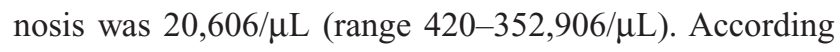
to the French-American-British (FAB) classification, three patients had AML M0, 62 had M1/M2, ten had M3, 21 had M4/M5, and ten had M7. Among 26 patients with extramedullary disease, 21 patients had chloroma (scalp in ten patients, orbit in six patients, and skin in five patients), and five patients had central nervous system involvement of leukemic cells. Cytogenetic classification was performed according to karyotyping. All patients were assigned to one of three cytogenetic risk groups: favorable (inv[16], t[16;16], $\mathrm{t}[9 ; 11], \mathrm{t}[8 ; 21])(2,17)$; intermediate (normal cytogenetics or not classifiable as favorable or adverse); and unfavorable $(-7,-5$, del [5q], abnormal 3q, or complex karyotype) $(2,17)$. Clinical characteristics of the patients with AML are summarized in Table 1.

The treatment for these patients was based on previous studies. ${ }^{22}$ Briefly, all patients with AML were treated with 10 days of induction chemotherapy, in which the dose of behenoyl 1-h-D-arabinofuranosylcytosine for the last 3 days was modified according to the bone marrow response on day 7 . Discontinuation of the chemotherapy was allowed in patients who experienced sepsis with unstable vital signs before the completion of the induction regimen if at least 7 days of induction chemotherapy had been provided. If complete remission was not achieved after the primary induction-chemotherapy regimen, an additional course of induction chemotherapy using high-dose 1-h-D-arabinofuranosylcytosine was given. 
Table I Characteristics of the 106 patients with pediatric acute myeloid leukemia

\begin{tabular}{|c|c|c|c|c|}
\hline \multirow[t]{2}{*}{ Clinical variables } & \multirow[t]{2}{*}{ Patients (n, \%) } & \multicolumn{2}{|c|}{ MiR- 100 expression $(n, \%)$} & \multirow[t]{2}{*}{$P$} \\
\hline & & Low & High & \\
\hline \multicolumn{5}{|l|}{ Sex } \\
\hline Male & $58(54.7)$ & $23(39.7)$ & $35(60.3)$ & \multirow[t]{2}{*}{0.6} \\
\hline Female & $48(45.3)$ & $15(31.3)$ & $35(68.7)$ & \\
\hline \multicolumn{5}{|l|}{ Age (years) } \\
\hline$>6$ & $40(37.7)$ & $10(25.0)$ & $30(75.0)$ & \multirow[t]{2}{*}{0.2} \\
\hline$\leq 6$ & $66(62.3)$ & $26(39.4)$ & $40(60.6)$ & \\
\hline \multicolumn{5}{|l|}{ Leukocytes $(/ \mu \mathrm{L})$} \\
\hline$>10,000$ & $66(62.3)$ & $22(33.3)$ & $44(66.7)$ & \multirow[t]{2}{*}{0.6} \\
\hline$\leq 10,000$ & $40(37.7)$ & $14(35.0)$ & $26(65.0)$ & \\
\hline \multicolumn{5}{|l|}{ FAB classification } \\
\hline MI-M6 & $96(90.6)$ & $35(36.5)$ & $61(63.5)$ & \multirow[t]{2}{*}{0.001} \\
\hline M7 & $10(9.4)$ & I (I0.0) & $9(90.0)$ & \\
\hline \multicolumn{5}{|c|}{ Extramedullary disease } \\
\hline Absent & $80(75.5)$ & $31(38.8)$ & $49(61.2)$ & \multirow[t]{2}{*}{0.008} \\
\hline Present & $26(24.5)$ & $5(19.2)$ & $21(80.8)$ & \\
\hline \multicolumn{5}{|l|}{ Cytogenetics* } \\
\hline Favorable & $35(33.0)$ & $20(20.0)$ & I5 (80.0) & \multirow[t]{3}{*}{0.3} \\
\hline Intermediate & $52(49.1)$ & $9(17.3)$ & $43(82.7)$ & \\
\hline Unfavorable & $19(17.9)$ & $7(36.8)$ & $12(63.2)$ & \\
\hline \multicolumn{5}{|c|}{ Day 7 response to treatment } \\
\hline Favorable & $65(6 \mid .3)$ & $26(40.0)$ & $39(60.0)$ & \multirow[t]{2}{*}{0.01} \\
\hline Unfavorable & $4 I(38.7)$ & $10(23.3)$ & 31 (76.7) & \\
\hline
\end{tabular}

Notes: *All patients were divided into three cytogenetic risk groups: favorable (inv[16], t[16;16], t[9;1 ]], t[8;2I]) $(2,17)$; intermediate (normal cytogenetics or not classifiable as favorable or unfavorable); and unfavorable $(-7,-5$, del $[5 q]$, abnormal 3q, or complex karyotype) $(2,17)$.

Abbreviations: MiR-100, microRNA-100; FAB, French-American-British.

Once complete remission had been achieved, patients with an appropriate stem-cell donor received consolidation chemotherapy until the hematopoietic stem-cell transplantation. An entire course of consolidation chemotherapy was given in patients without an appropriate stem-cell donor.

The control group consisted of 20 normal healthy children (3-18 years, median 6 years, eleven boys and nine girls) with no previous history of infection or malignancy and normal bone marrow morphology as demonstrated by cytological and histological analyses.

\section{Real-time quantitative RT-PCR for miRNA}

To evaluate miR-100 expression in bone marrow mononuclear cells, real-time quantitative reverse transcription (RT)-PCR for miRNA was performed in this study. Mononuclear cells were isolated by Ficoll-Hypaque density gradient centrifugation of $2 \mathrm{~mL}$ bone marrow samples in ethylenediaminetetraacetic acid from newly diagnosed patients and control samples. Total RNA was extracted using Trizol reagent (Life Technologies Corporation, Carlsbad, CA) according to the manufacturer's instructions. The miR-100 and RNU6B (as an internal control)-specific cDNA were synthesized from total RNA using gene-specific primers according to the TaqMan MicroRNA assays protocol (assay ID 000437; Applied Biosystems, Foster City, CA). The following primers were used: for RNU6B, forward primer, 5'-CGC TTC GGC AGC ACA TAT AC-3'; reverse primer, 5'-TTC ACG AAT TTG CGT GTC AT-3'; for MiR-100, 5'-AAC CCG TAG ATC CGA ACT TG-3'; reverse primer: 5'-TAC CTA TAG ATA CAA GCT TGT GCG-3'. RT conditions contained, as previously described, ${ }^{23} 10 \mathrm{ng}$ of total RNAs, $50 \mathrm{nmol} / \mathrm{L}$ stem-loop RT primer, $1 \times$ RT buffer, $0.3 \mathrm{mmol} / \mathrm{L}$ each of deoxynucleotide triphosphate, $3.3 \mathrm{U} / \mu \mathrm{L}$ MultiScribe (Applied Biosystems) reverse transcriptase, and $0.3 \mathrm{U} / \mu \mathrm{L}$ RNase inhibitor. The 7.5- $\mu \mathrm{L}$ reaction volumes were incubated in Bio-Rad i-Cycler (Bio-Rad Laboratories, Hercules, CA) in a 96-well plate for 30 minutes at $16^{\circ} \mathrm{C}, 30$ minutes at $42^{\circ} \mathrm{C}$, 5 minutes at $85^{\circ} \mathrm{C}$, and then held at $4^{\circ} \mathrm{C}$. Real-time PCR was performed using an Applied Biosystems 7500 real-time PCR system according to the protocol of a previous study. ${ }^{23}$ The $10-\mu \mathrm{L}$ PCR included $0.7 \mu \mathrm{L}$ of RT products, $1 \times$ TaqMan Universal PCR master mix, and $1 \mu \mathrm{L}$ of primers and probe mix of the TaqMan MicroRNA Assays. The reactions were incubated in 96-well optical plates at $95^{\circ} \mathrm{C}$ for 10 minutes, followed by 45 cycles of $95^{\circ} \mathrm{C}$ for 15 seconds and $60^{\circ} \mathrm{C}$ for 10 minutes. Relative quantification of target miRNA expression was evaluated using the comparative cycle threshold method. 
The raw data were presented as the relative quantity of target miRNA, normalized with respect to RNU6B. For each sample, all experiments were done in triplicate. Mean normalized gene expression \pm standard error was calculated from three independent experiments.

\section{Statistical analysis}

SPSS version 16.0 (IBM, Armonk, NY) and SAS 9.1 (SAS Institute, Cary, NC) were used for statistical analysis. With regard to the correlation of leukemia clinical features with the expression level of miRNA-100, intergroup comparisons were performed using one-way analysis of variance (ANOVA). When the equal-variance test or normality test failed, the Kruskall-Wallis nonparametric test was applied. To address the problem of multiple comparisons, these tests (ANOVA, Kruskall-Wallis) were followed by a post hoc Bonferroni test. Kaplan-Meier survival curves were used to determine any significant relationship between the expression level of miRNA-100 and the status of the patients with respect to relapse-free survival (RFS) or overall survival (OS). Differences were considered statistically significant when $P$ was less than 0.05 .

\section{Results}

\section{MiRNA- 100 expression in AML patients}

MiRNA-100 expression was detected in bone marrow from patients with pediatric AML and normal controls. Expression of miRNA-100 was normalized with RNU6B, and the values obtained were compared. Compared with the normal controls, we showed upregulation of miR-100 in the bone marrow of pediatric AML patients with statistically significant differences $(P<0.001$, Figure 1). AML patients expressing miR-100 at levels less than the median expression level (10.8) were assigned to the low-expression group (mean expression value 10.6, $\mathrm{n}=36$ ), and those samples with expression equal or above the median value were assigned to the high-expression group (mean expression value $10.9, \mathrm{n}=70$ ).

\section{Association of miR- 100 expression with clinical characteristics of pediatric $A M L$ patients}

The association of miR-100 expression with clinical characteristics at diagnosis is summarized in Table 1. The expression levels of miR-100 were found to be significantly higher in pediatric AML patients with extramedullary disease, with the FAB classification subtype M7, and with unfavorable

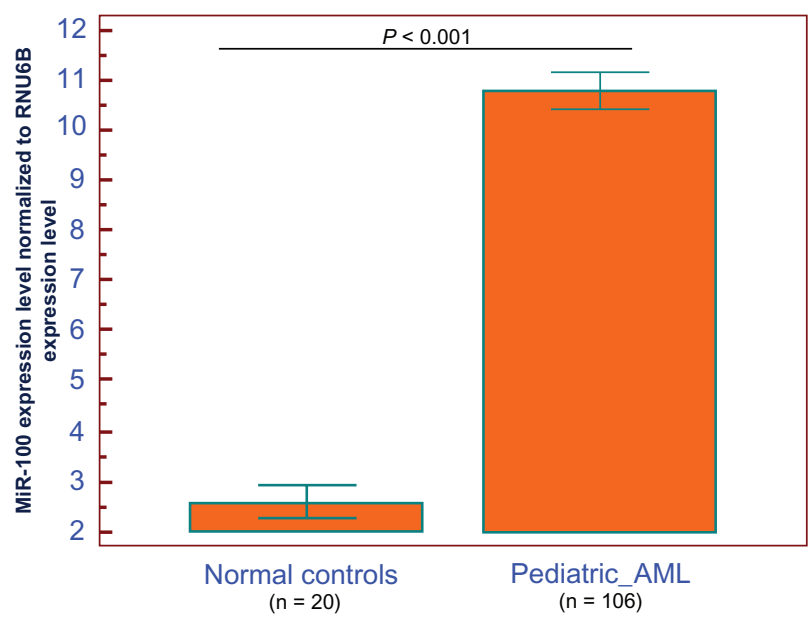

Figure I MicroRNA-100 (miR-100) expression in 106 pediatric acute myeloid leukemia (AML) patients and normal controls.

Notes: After normalization to RNU6B expression levels, the expression level of miR100 in the bone marrow of 106 pediatric AML patients (mean \pm standard deviation [SD]: $10.8 \pm 1.9$ ) was significantly higher than that of normal controls (mean $\pm S D$ : $2.6 \pm 0.7, P<0.00$ I). $P$-values were calculated using the Mann-Whitney $U$ test.

day 7 response to induction chemotherapy $(P=0.008,0.001$, and 0.01 , respectively, Table 1$)$. There was no significant association of miR-100 expression level with patients' sex and age, leukocyte count, or cytogenetic abnormalities (all $P>0.05$, Table 1).

\section{Association of miR- 100 expression with clinical outcome of pediatric AML patients}

Follow-up data were available for all patients. The median follow-up duration was 35 months, ranging from 10 to 86 months. Univariate analysis of factors associated with RFS showed a significantly shorter survival in the patients with FAB classification subtype M7 $(P=0.01)$, unfavorable cytogenetic abnormalities $(P<0.001)$, and higher miR-100 expression $(P=0.008$, Table 2$)$. Parameters such as patients' sex and age, leukocyte counts, the presence of extramedullary disease, and day 7 response to treatment had no impact (all $P>0.05$, data were not shown). On the other hand, the variables that were associated with poor OS on univariate analysis were also FAB classification subtype M7 $(P=0.008)$, unfavorable cytogenetic abnormalities $(P<0.001)$, and higher miR-100 expression $(P=0.006$, Table 2). Cox proportional-hazards multivariate analysis of the univariate predictors identified the cytogenetic abnormalities $(P=0.01$ and 0.009 , respectively) and the expression level of miR-100 ( $P=0.03$ and 0.01 , respectively) as independent prognostic factors for RFS and OS (Table 3). The Kaplan-Meier curves for RFS and OS stratified according 
Table 2 Univariate analysis of the impact of variables on relapse-free and overall survival in pediatric acute myeloid leukemia patients

\begin{tabular}{|c|c|c|c|c|c|}
\hline \multirow[t]{2}{*}{ Variable } & \multirow[t]{2}{*}{ Patients (n) } & \multicolumn{2}{|l|}{ Relapse-free survival } & \multicolumn{2}{|l|}{ Overall survival } \\
\hline & & Median (months \pm SD) & $P$ & Median (months \pm SD) & $P$ \\
\hline \multicolumn{6}{|l|}{ Cytogenetics } \\
\hline Favorable & 35 & Not reached & $<0.001$ & Not reached & $<0.001$ \\
\hline Intermediate & 52 & $12.6 \pm 1.8$ & & $22.9 \pm 2.1$ & \\
\hline Unfavorable & 19 & $3.1 \pm 0.5$ & & $9.8 \pm 1.7$ & \\
\hline \multicolumn{6}{|l|}{ FAB classification } \\
\hline MI-M6 & 96 & $14.3 \pm 2.2$ & 0.01 & $36.2 \pm 3.8$ & 0.008 \\
\hline M7 & 10 & $7.9 \pm 1.4$ & & $20.7 \pm 2.5$ & \\
\hline \multicolumn{6}{|c|}{ MiR-I00 expression } \\
\hline Low $(<10.8)$ & 36 & $12.9 \pm 1.6$ & 0.008 & $37.4 \pm 3.1$ & 0.006 \\
\hline High $(\geq 10.8)$ & 70 & $5.8 \pm 0.8$ & & $22.7 \pm 2.9$ & \\
\hline
\end{tabular}

Abbreviations: SD, standard deviation; FAB, French-American-British; MiR-100, microRNA-100.

to $\mathrm{miR}-100$ expression in bone marrow from pediatric $\mathrm{AML}$ patients are shown in Figure 2.

\section{Discussion}

Increased expression of miR-100 in AML has been demonstrated to regulate $\mathrm{G} 1 / \mathrm{S}$ transition and S-phase entry and block terminal differentiation, which in turn promotes cell proliferation and blocked granulocyte/monocyte differentiation. ${ }^{21}$ However, the clinical relevance of miR-100 remains largely elusive, and there have been no studies on the prognostic relevance of miR-100 expression in pediatric AML to date. In this context, the present study was performed to investigate the possible association between miR-100 expression and the clinical features in pediatric de novo AML. There are three significant findings according to our results: miR-100 expression was elevated in bone marrow from pediatric patients with newly diagnosed AML, compared with normal controls;

Table 3 Multivariate analysis of the impact of variables on relapse-free survival and overall survival in pediatric acute myeloid leukemia patients

\begin{tabular}{lll}
\hline Variable & $P$ & Odds ratio \\
\hline $\begin{array}{l}\text { Relapse-free survival } \\
\text { Cytogenetics } \\
\quad \text { Unfavorable vs favorable/intermediate }\end{array}$ & 0.01 & 5.9 \\
$\begin{array}{l}\text { FAB classification } \\
\quad \text { M7 vs MI-M6 }\end{array}$ & 0.06 & 2.3 \\
$\begin{array}{l}\text { MiR-I00 expression } \\
\quad \text { High vs low }\end{array}$ & 0.03 & 3.6 \\
$\begin{array}{l}\text { Overall survival } \\
\text { Cytogenetics } \\
\quad \text { Unfavorable vs favorable/intermediate }\end{array}$ & 0.009 & 7.1 \\
$\begin{array}{l}\text { FAB classification } \\
\quad \text { M7 vs MI-M6 }\end{array}$ & 0.06 & 2.5 \\
$\begin{array}{l}\text { MiR-I00 expression } \\
\text { High vs Low }\end{array}$ & 0.01 & 5.2 \\
\hline
\end{tabular}

Abbreviations: $F A B$, French-American-British; MiR-100, microRNA-100. increased expression of miR-100 was significantly associated with advanced clinical features of pediatric AML patients; and both univariate and multivariate analyses revealed that the expression level of miR-100 was predictive of shorter RFS and OS, independent of cytogenetic abnormalities. These results suggest that miR-100 expression could be a valuable marker of progression and prognosis in pediatric AML. To our knowledge, this is the first study to analyze the expression patterns and clinical significance of miR-100 in a large number of pediatric AML patients.

MiR-100, as a potential tumor-related miRNA, has been reported to be involved in tumor occurrence, development, and drug resistance. ${ }^{24}$ Expression patterns and functional role of miR-100 in different cancers are controversial. For example, Huang et $\mathrm{a}^{25}$ reported that downregulation of miR-100 was significantly associated with advanced International Federation of Gynaecology and Obstetrics stage, presence of lymph-node metastasis, and reduced survival of small-cell carcinoma of the cervix patients, while Dahiya et $\mathrm{al}^{26}$ noted that miR-100 was overexpressed in ovarian cancer cell lines and tissues,
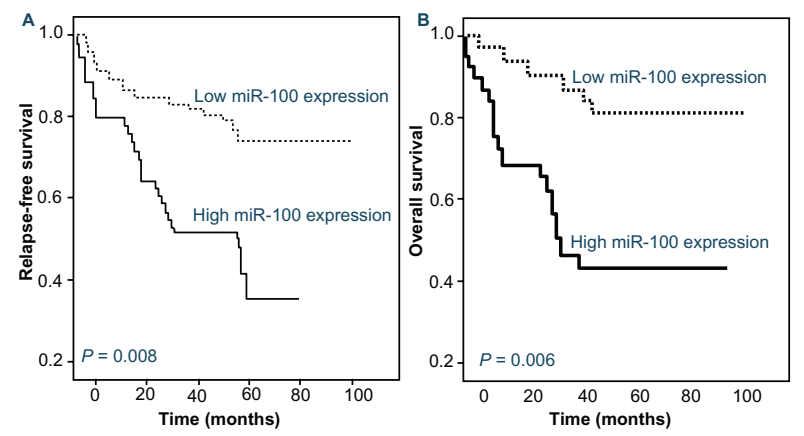

Figure 2 Kaplan-Meier curves of relapse-free survival (A) and overall survival (B) of pediatric patients with newly diagnosed acute myeloid leukemia (AML) stratified by the level of microRNA-I00 (miR-100) expression.

Notes: High miR-100 expression was associated with shorter relapse-free $(P=0.008)$ and overall $(P=0.006)$ survival in pediatric AML patients. 
mostly in serous high-grade adenocarcinoma. Peng et $\mathrm{al}^{27}$ found that low miR-100 expression may be an independent poor prognostic factor for human epithelial ovarian cancer. Leite et $\mathrm{al}^{28}$ demonstrated that the upregulation of miR-100 was associated with the biochemical recurrence of localized prostate cancer in patients treated with radical prostatectomy. $\mathrm{Ng}$ et $\mathrm{al}^{29}$ suggested that miR-100 is highly expressed in the human glioma cell line and its upregulation could be a useful tool to sensitize tumor cells to ionizing radiation. Shi et $\mathrm{al}^{30}$ indicated that underexpressed miR-100 in human nasopharyngeal cancer contributes to tumor progression. More interestingly, miR-100 is significantly upregulated in adult AML patients and AML cell lines, which raises the possibility that miR-100 might have an important role in the development or pathogenesis of AML. ${ }^{21}$ In this study, we performed large retrospective studies in order to determine the association of miR-100 expression with clinicopathologic features and clinical outcome of pediatric AML patients. Using 106 clinical de novo pediatric AML patients and 20 normal controls, our study has provided the first evidence that miR-100 expression is markedly increased in de novo pediatric AML patients. This finding is consistent with previous studies revealing that the miR-100 level is highly elevated in adult AML patients and AML cell lines. ${ }^{21}$ In addition, increased expression of miR-100 was significantly associated with the presence of extramedullary disease, FAB classification subtype M7, and unfavorable day 7 response to induction chemotherapy. Moreover, the most important finding of this study was that pediatric AML patients with high miR-100 expression had a poorer prognosis than did those with low miR-100 expression. The above results validate previous in vitro findings that miR-100 functions as a tumor promoter during the development and progression of human AML. ${ }^{17}$

In conclusion, this is the first report demonstrating the upregulation of miR-100 in pediatric AML, and its association with poor RFS and OS. These results suggest that miR100 upregulation may be used as an unfavorable prognostic marker in pediatric AML. Recent research has demonstrated that miR-100 may regulate neovascularization by suppressing the expression of its target-gene mammalian target of rapamycin in endothelial and vascular smooth muscle cells. ${ }^{31}$ Thus, we assume that upregulation of miR-100 in AML patients might be related to their condition, considering the target genes for this microRNA. This hypothesis warrants further prospective analysis.

\section{Disclosure}

The authors report no conflicts of interest in this work.

\section{References}

1. Deschler B, Lubbert M. Acute myeloid leukemia:epidemiology and etiology. Cancer. 2006;107:2099-2107.

2. Tiedemann K, Waters KD, Tauro GP, Tucker D, Ekert H. Results of intensive therapy in childhood acute myeloid leukemia, incorporating high-dose melphalan and autologous bone marrow transplantation in first complete remission. Blood. 1993;82:3730-3738.

3. Sung KW, Choi J, Hwang YK, et al. Overexpression of X-linked inhibitor of apoptosis protein (XIAP) is an independent unfavorable prognostic factor in childhood de novo acute myeloid leukemia. J Korean Med Sci. 2009;24:605-613.

4. Grimwade D, Hills RK, Moorman AV, et al. Refinement of cytogenetic classification in acute myeloid leukemia: determination of prognostic significance of rare recurring chromosomal abnormalities among 5876 younger adult patients treated in the United Kingdom Medical Research Council trials. Blood. 2010;116:354-365.

5. Kang HJ, Lee JW, Kho SH, et al. High transcript level of FLT3 associated with high risk of relapse in pediatric acute myeloid leukemia. J Korean Med Sci. 2010;25:841-845.

6. Rubnitz JE, Gibson B, Smith FO. Acute myeloid leukemia. Pediatr Clin North Am. 2008;55:21-51, ix.

7. Hollink IH, van den Heuvel-Eibrink MM, Zimmermann M, et al. Clinical relevance of Wilms tumor 1 gene mutations in childhood acute myeloid leukemia. Blood. 2009;113:5951-5960.

8. Esteller M. Non coding RNAs in human disease. Nat Rev Genet. 2011;12: 861-874.

9. van Kouwenhove M, Kedde M, Agami R. MicroRNA regulation by RNA binding proteins and its implications for cancer. Nat Rev Cancer. 2011;11:644-656.

10. Dela Cruz F, Matushansky I. MicroRNAs in chromosomal translocation associated solid tumors:learning from sarcomas. Discov Med. 2011;12:307-317.

11. Zhang H, Luo XQ, Zhang P, et al. MicroRNA patterns associated with clinical prognostic parameters and CNS relapse prediction in pediatric acute leukemia. PLoS One. 2009;4:e7826.

12. Rücker FG, Russ AC, Cocciardi S, et al. Altered miRNA and gene expression in acute myeloid leukemia with complex karyotype identify networks of prognostic relevance. Leukemia. Epub July 19, 2012.

13. Cimmino A, Calin GA, Fabbri M, et al. miR-15 and miR-16 induce apoptosis by targeting BCL2. Proc Natl Acad Sci U S A. 2005;102: 13944-13949.

14. Lopotová T, Záčková M, Klamová H, Moravcová J. MicroRNA-451 in chronic myeloid leukemia: miR-451-BCR-ABL regulatory loop? Leuk Res. 2011;35:974-977.

15. Eyholzer M, Schmid S, Wilkens L, Mueller BU, Pabst T. The tumoursuppressive miR-29a/b1 cluster is regulated by CEBPA and blocked in human AML. Br J Cancer. 2010;103:275-284.

16. Henson BJ, Bhattacharjee S, O'Dee DM, Feingold E, Gollin SM. Decreased expression of miR-125b and miR-100 in oral cancer cells contributes to malignancy. Genes Chromosomes Cancer. 2009;48: 569-582.

17. Doghman M, El Wakil A, Cardinaud B, et al. Regulation of insulin-like growth factor-mammalian target of rapamycin signaling by microRNA in childhood adrenocortical tumors. Cancer Res. 2010;70:4666-4675.

18. Cairo S, Wang Y, de Reyniès A, et al. Stem cell-like micro-RNA signature driven by Myc in aggressive liver cancer. Proc Natl Acad Sci USA. 2010;107:20471-20476.

19. Nagaraja AK, Creighton CJ, Yu Z, et al. A link between mir-100 and FRAP1/mTOR in clear cell ovarian cancer. Mol Endocrinol. 2010;24:447-463.

20. Oliveira JC, Brassesco MS, Morales AG, et al. MicroRNA-100 acts as a tumor suppressor in human bladder carcinoma 5637 cells. Asian Pac J Cancer Prev. 2011;12:3001-3004.

21. Zheng YS, Zhang H, Zhang XJ, et al. MiR-100 regulates cell differentiation and survival by targeting RBSP3, a phosphatase-like tumor suppressor in acute myeloid leukemia. Oncogene. 2012;31: 80-92. 
22. Sung KW, Choi J, Hwang YK, et al. Overexpression of X-linked inhibitor of apoptosis protein (XIAP) is an independent unfavorable prognostic factor in childhood de novo acute myeloid leukemia. J Korean Med Sci. 2009;24:605-613.

23. Motoyama K, Inoue $\mathrm{H}$, Mimori $\mathrm{K}$, et al. Clinicopathological and prognostic significance of PDCD4 and microRNA-21 in human gastric cancer. Int J Oncol. 2010;36:1089-1095.

24. Dai Y, Xie CH, Neis JP, Fan CY, Vural E, Spring PM. MicroRNA expression profiles of head and neck squamous cell carcinoma with docetaxelinduced multidrug resistance. Head Neck. 2011;33:786-791.

25. Huang L, Lin JX, Yu YH, Zhang MY, Wang HY, Zheng M. Downregulation of six microRNAs is associated with advanced stage, lymph node metastasis and poor prognosis in small cell carcinoma of the cervix. PLoS One. 2012;7:e33762.

26. Dahiya N, Sherman-Baust CA, Wang TL, et al. Micro RNA expression and identification of putative miRNA target in ovarian cancer. PLoS One. 2008;3:e2436.
27. Peng DX, Luo M, Qiu LW, He YL, Wang XF. Prognostic implications of microRNA-100 and its functional roles in human epithelial ovarian cancer. Oncol Rep. 2012;27:1238-1244.

28. Leite KR, Tomiyama A, Reis ST, et al. MicroRNA expression profiles in the progression of prostate cancer - from high-grade prostate intraepithelial neoplasia to metastasis. Urol Oncol. Epub August 29, 2011.

29. Ng WL, Yan D, Zhang X, Mo YY, Wang Y. Over-expression of miR100 is responsible for the low expression of ATM in the human glioma cell line: M059J. DNA Repair (Amst). 2010;9:1170-1175.

30. Shi W, Alajez NM, Bastianutto C, et al. Significance of Plk1 regulation by miR-100 in human nasopharyngeal cancer. Int $J$ Cancer. 2010;126:2036-2048.

31. Grundmann S, Hans FP, Kinniry S, et al. MicroRNA-100 regulates neovascularization by suppression of mammalian target of rapamycin in endothelial and vascular smooth muscle cells. Circulation 2011;123:999-1009.

\section{Publish your work in this journal}

OncoTargets and Therapy is an international, peer-reviewed, open access journal focusing on the pathological basis of all cancers, potential targets for therapy and treatment protocols employed to improve the management of cancer patients. The journal also focuses on the impact of management programs and new therapeutic agents and protocols on

\section{Dovepress}

patient perspectives such as quality of life, adherence and satisfaction The manuscript management system is completely online and includes a very quick and fair peer-review system, which is all easy to use. Visit http://www.dovepress.com/testimonials.php to read real quotes from published authors. 